\title{
Investigating the Impact of Shading Effect on the Characteristics of a Large-Scale Grid-Connected PV Power Plant in Northwest China
}

\author{
Yunlin Sun, ${ }^{1,2}$ Siming Chen, ${ }^{2}$ Liying Xie, ${ }^{1}$ Ruijiang Hong, ${ }^{1,2}$ and Hui Shen ${ }^{1,2}$ \\ ${ }^{1}$ Institute for Solar Energy Systems, School of Physics and Engineering, Sun Yat-sen University, \\ Guangzhou Higher Education Mega Center, Guangzhou, Guangdong Province 510006, China \\ ${ }^{2}$ Shunde SYSU Institute for Solar Energy, No. 1, Desheng Dong Road, Daliang, Shunde, Foshan, Guangdong Province 528300, China
}

Correspondence should be addressed to Ruijiang Hong; hongruij@mail.sysu.edu.cn and Hui Shen; shenhuil956@163.com

Received 3 January 2014; Accepted 18 January 2014; Published 5 March 2014

Academic Editor: Hongxing Yang

Copyright (C) 2014 Yunlin Sun et al. This is an open access article distributed under the Creative Commons Attribution License, which permits unrestricted use, distribution, and reproduction in any medium, provided the original work is properly cited.

Northwest China is an ideal region for large-scale grid-connected PV system installation due to its abundant solar radiation and vast areas. For grid-connected PV systems in this region, one of the key issues is how to reduce the shading effect as much as possible to maximize their power generation. In this paper, a shading simulation model for PV modules is established and its reliability is verified under the standard testing condition (STC) in laboratory. Based on the investigation result of a $20 \mathrm{MWp}$ gridconnected PV plant in northwest China, the typical shading phenomena are classified and analyzed individually, such as power distribution buildings shading and wire poles shading, plants and birds droppings shading, and front-row PV arrays shading. A series of experiments is also conducted on-site to evaluate and compare the impacts of different typical shading forms. Finally, some feasible solutions are proposed to avoid or reduce the shading effect of PV system during operation in such region.

\section{Introduction}

Most of the large-scale PV power systems are usually installed in the areas with adequate solar resources and vast land. For example, northwest China, where gobies, desert, and shoals are widely distributed, is an ideal region for large-scale application of PV systems. Meanwhile, the annual average solar irradiation in most of northwest China is in a range from $5400 \mathrm{MJ} / \mathrm{m}^{2} \cdot$ yr. to $6700 \mathrm{MJ} / \mathrm{m}^{2} \cdot \mathrm{yr}$. Comparing to that in Germany, about $3600 \mathrm{MJ} / \mathrm{m}^{2} \cdot \mathrm{yr}$. [1], northwest China has greater potential for developing PV power plants.

However, in practical application, certain blocks, such as leafs and bird droppings from the natural environment, the shadows of wire poles, power distribution buildings, or even the shadows of front row PV arrays on the modules due to the improper design or the limitations of natural condition, will greatly impact the performance of PV arrays. It is reported that the causes of hot-spots on PV modules can be attributed to partial shading or uneven distribution of light intensity [25]. Hot-spot is defined as a localized region in a solar cell/PV module whose operating temperature is obviously higher than its surrounding area, which will cause less current and become a reverse diode to the rest of parts of solar cells/PV modules connected in series. As a result, hot-spots would seriously reduce the performance of the partial shaded solar cells and PV modules, or even cause a potential irreversible damage to the PV modules, such as tedlar delamination and fire disaster $[6,7]$.

Generally, in PV modules level, the most common method to avoid hot-spots effect is to connect a bypass diode in parallel with reverse polarity for a group of solar cells, typically 18 or 20 pieces of solar cells in a group. Thus, the partial shaded cell is reverse biased while the bypass diode is forward conducted, which bypasses the excessive current and almost short circuits the group of cells in some degree which depends on the proportion of shadow area in one solar cell. The protection by using bypass diodes is simple and general method used in commercial PV products. However, less field research about the performance of PV modules with bypass diodes under partial shading is conducted. In this paper, a 


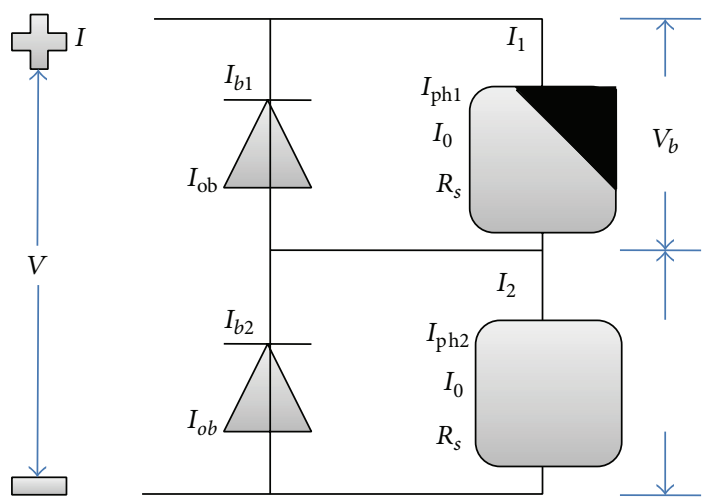

FIGURE 1: Equivalent circuit of a PV module with partial shading.

shading simulation model for PV modules is established and its reliability is verified under the standard testing condition (STC) in laboratory. The $I-V$ and $P-V$ characteristics of a 20MWp grid-connected PV plant were also measured on-site to analyze the impacts of different types of partial shading. Finally some feasible solutions are proposed to avoid or reduce the shading effect during PV system operation in such region.

\section{Shading Model}

2.1. Shading Model for PV Modules. As shown in Figure 1, an equivalent circuit of a PV module is simplified into two cells in series with two bypass diodes. The parameters of these two cells and diodes are assumed to be constant, and the bypass diodes will shut down if the two cells receiving equal irradiation. Based on the commonly used single diode solar cell model, the output current $I$ through the load is given by (1), where the effect of the very large shunt resistance $R_{\mathrm{SH}}$ is ignored $[8,9]$ :

$$
I=I_{\mathrm{ph}}-I_{0}\left\{\exp \left[\frac{q \cdot\left(V+I R_{S}\right)}{A k T}\right]-1\right\},
$$

where $I_{\mathrm{ph}}$ and $I_{0}$ are the photocurrent and the inverse saturation current, respectively. $R_{S}$ is the series resistance. $A$ and $T$ are the ideality factor of the diode and temperature in Kelvin, respectively; $q$ is electron charge $\left(1.6 \times 10^{-19} \mathrm{C}\right)$ and $k$ is Boltzmann's constant $\left(1.38 \times 10^{-23} \mathrm{~J} / \mathrm{K}\right)$.

The current $I_{b}$ through the bypass diode is given by

$$
I_{b}=I_{o b}\left\{\exp \left[\frac{-q V}{A_{b} k T_{b}}\right]-1\right\} .
$$

As shown in Figure 1, a shadow falling on cell 1 reduced the energy input to the cell and consequently increased the energy loss in this partial shaded cell, while cell 2 is connected with cell lin series and under full illumination. Hence, the photocurrent, $I_{\mathrm{ph} 2}$, is higher than that of the shaded cell, $I_{\mathrm{ph} 1}$. The states of the bypass diode connecting in parallel with cell 1 are in two cases depending on the different level of output voltage $V$.
(1) In the case of $I_{\mathrm{ph} 1}<I \leq I_{\mathrm{ph} 2}$, the output current $I$ is almost equal to short circuit current $I_{\mathrm{SC}}$ when the output voltage $V$ is relatively low. If there were no bypass diodes, the partial shaded cell 1 would be reverse biased and offer high resistance in the circuit, which results in consuming power and reducing the output current $I$. In this case, the bypass diode 1 connected with cell 1 in parallel is forward biased; then the redundant current $I-I_{\text {phl }}$ flows through the bypass diode to protect the shaded cell 1 against the shading effect and hot-spots. The output power is mainly contributed by the solar cell 2 that is under full illumination.

(2) As the output voltage $V$ increases, the output current $I$ turns out to be in the case of $0 \leq I \leq I_{\text {ph1 } 1}$ and the shaded cell 1 is forward biased while the bypass diode 1 is in the state of shutting down as it is reverse biased. There is no risk for the shaded cell.

It is demonstrated that the output characteristics of the partial shaded PV module are different from those of the module fully illuminated because of the reduced luminous energy input. Besides, due to the existence of a bypass diode, as shown in Figure 1, the shaded cell is protected from damage of hot-spots. The $I-V$ curve of the partial shaded PV module is described by a piecewise function (3), which breaks at the point of the state switching of the bypass diode:

$$
\begin{aligned}
V= & \frac{A k T}{q} \ln \left(\frac{I_{\mathrm{ph} 2}-I}{I_{0}}+1\right) \\
& -\frac{A_{b} k T_{b}}{q} \ln \left(\frac{I-I_{\mathrm{ph} 1}}{I_{o b}}+1\right)-I R_{S}, \\
I_{\mathrm{ph} 1}<I \leq I_{\mathrm{ph} 2}, & \\
V= & \frac{A k T}{q} \ln \left(\frac{I_{\mathrm{ph} 1}-I}{I_{0}}+1\right) \\
& -\frac{A k T}{q} \ln \left(\frac{I_{\mathrm{ph} 2}-I}{I_{0}}+1\right)-2 I R_{S}, \\
\quad 0 & \leq I \leq I_{\mathrm{ph} 1} .
\end{aligned}
$$

All above-mentioned the shading model analysis of PV module theoretically infers that a PV module containing $N$ pieces of solar cells is divided into $K$ groups by connecting $K$ bypass diodes in parallel ( $N \geq K$, not overlapping). If shadows fell on the solar cells in different proportion for every group, the $I-V$ curve of the PV module would show $K$ steps and there are corresponding $K$ peaks in $P$ - $V$ curve $[10,11]$.

2.2. Experimental Verification. In order to verify the presented model, some experimental measurements have been carried out by using a commercial PV module ( $54 \mathrm{Wp}$, KC50T-1 produced by KYOCERA in Japan). The module includes two bypass diodes and 36 solar cells connected in series. The main parameters of the PV module at standard testing condition (AM 1.5, $\left.1000 \mathrm{~W} / \mathrm{m}^{2}, 25^{\circ} \mathrm{C}\right)$ are shown in 


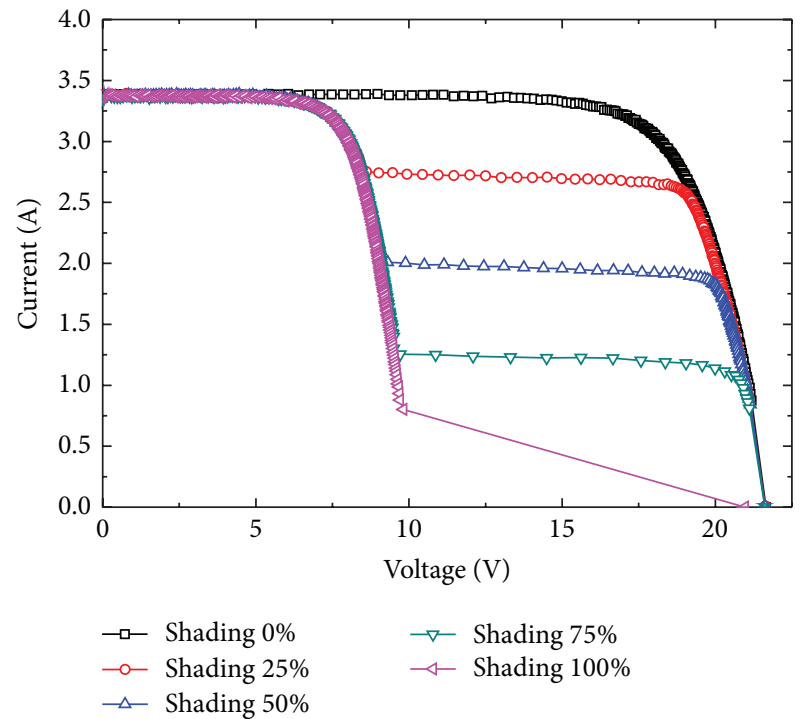

(a)

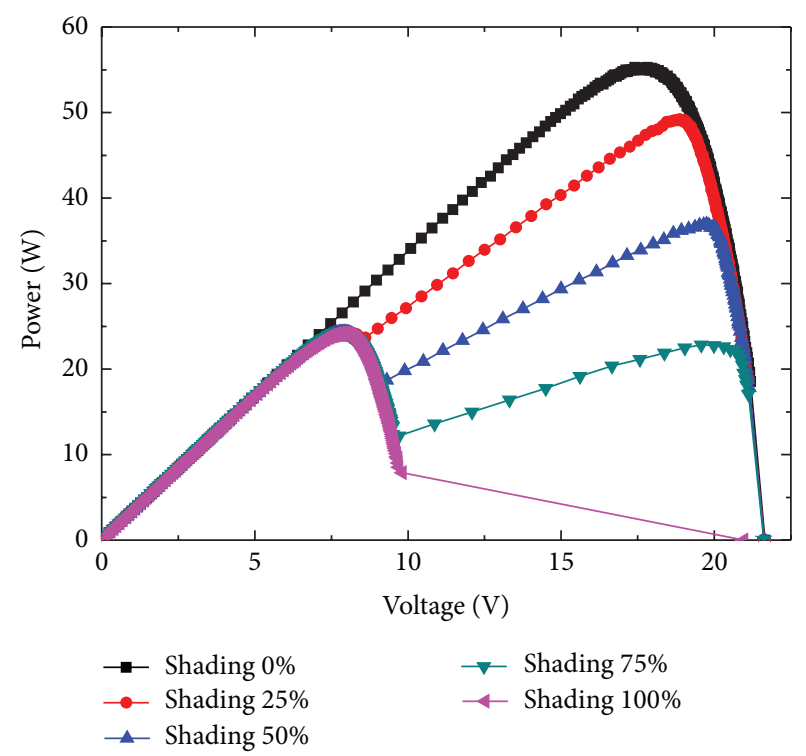

(b)

FIGURE 2: The output characteristics of KC50T-1 PV Module under 0\%, 25\%, 50\%, 75\%, and 100\% shading on a single solar cell in one of the two groups which are parallel connected with two bypass diodes. (a) $I-V$ curves and (b) $P-V$ curves.

TABLE 1: Main parameters of the PV module used in shading model verification experiments (STC).

\begin{tabular}{lc}
\hline Sample & KC50T-1 \\
\hline$V_{\text {oc }} V_{\text {oc }}(\mathrm{V})$ & 21.7 \\
$I_{\text {sc }}(\mathrm{A})$ & 3.31 \\
$V_{\text {mpp }}(\mathrm{V})$ & 17.4 \\
$I_{\text {mpp }}(\mathrm{A})$ & 3.11 \\
$P_{\text {mpp }}(\mathrm{W})$ & 54 \\
\hline
\end{tabular}

Table 1. The $I-V$ and $P-V$ characteristics of the PV module under shading rates of $0 \%, 25 \%, 50 \%, 75 \%$, and $100 \%$ on a single solar cell, as shown in Figure 2, were measured, respectively, by an OPTOSOLAR Module Tester made in Germany. Table 2 lists the main measurement parameters comparing with the nominal ones corresponding to Figure 2.

From Figure 2 and Table 2, it is seen that the open circuit voltages $\left(V_{\mathrm{oc}}\right)$ and short circuit currents $\left(I_{\mathrm{sc}}\right)$ are almost not varied with the variation of shading proportion. Considering that the PV module is divided into two groups by parallel connecting two bypass diodes without overlapping [8], all the shading $I-V$ curves in Figure 2 show two steps while two peaks in $P-V$ curves. The photocurrent $I_{\mathrm{ph}}$ is proportional to the solar cell active area, so it is found that the currents of latter half of the $I-V$ curves, where the bypass diodes are not at conducting state, were reduced relatively to the shading rate. At low voltage values, a new local maximum power point appears in the $P-V$ curves, which may be the new maximum power point depending on the shading proportion and the value of the breakdown voltage of the shaded cell. However, the straight lines appearing in the $I-V$ and $P-V$ curves of $100 \%$ shadow over the solar cell is attributed to the device's low precision in this range. The output characteristics, obtained from the experiments results mentioned above, agree well with the developed shading model.

\section{Results and Discussion}

3.1. Shading Types Classification. Some different types of shading falling on the PV modules were observed in a 20MWp grid-connected PV plant in northwest China [12-14]. And they can be classified into three types, namely, (1) power distribution buildings and wire poles shading, (2) plants and bird droppings shading, and (3) shading caused by front rows of PV array.

3.1.1. Power Distribution Buildings and Wire Poles Shading. Setting up electricity poles and wires is to collect and transport the electricity power produced by PV arrays. Some power distribution buildings are also necessary for PV plant to place inverters, transformers, and other equipment. However, some shadings and shadows would be formed and fall on the PV arrays, if the positions of power distribution buildings and wire poles were laid out inappropriately and too close to the PV modules, as shown in Figures 3(a) and 3(b). It is found that the shadows of the power distribution building and wire pole spread over several PV modules or even the whole PV array.

3.1.2. Plants and Bird Droppings Shading. As we know, developing PV power generation is eco-friendly to the ecology and environment of northwest China. Since desertification is so serious in there, both economic and environmental benefits can be obtained by desertification control and ecological environment protection. It was found that plants around PV 


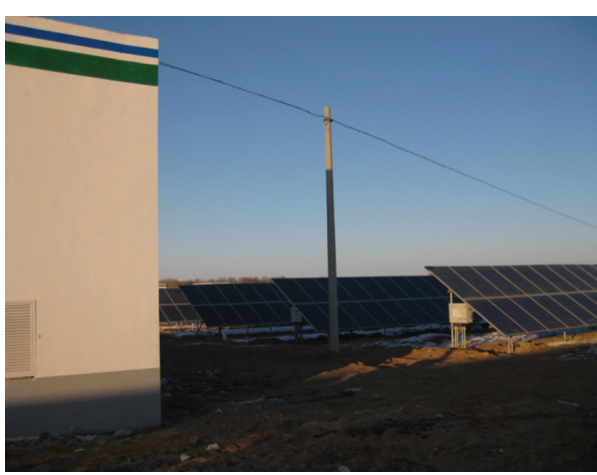

(a)

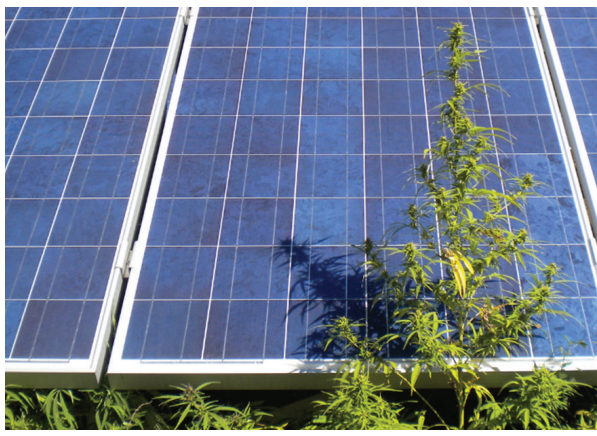

(c)

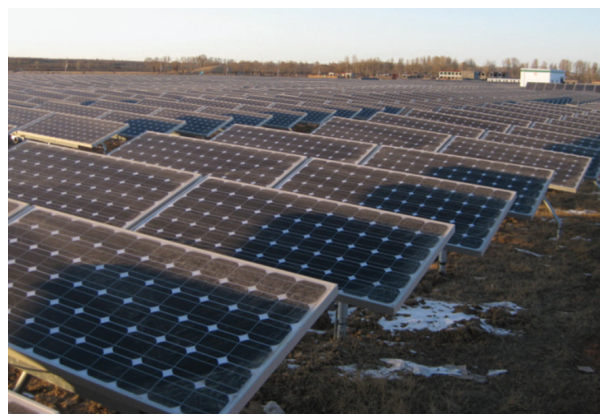

(e)

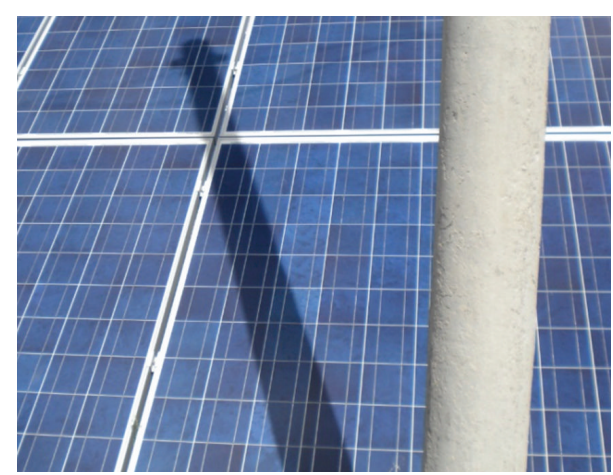

(b)

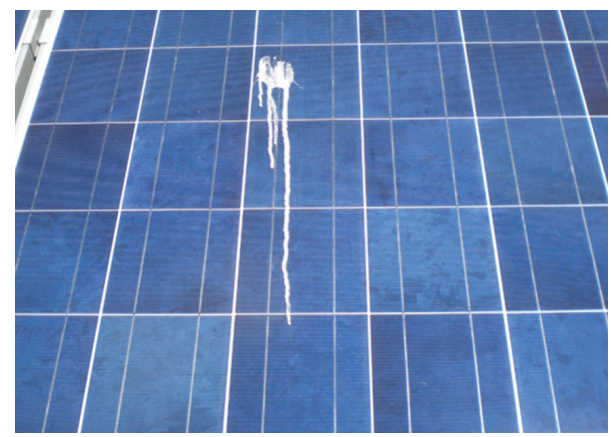

(d)

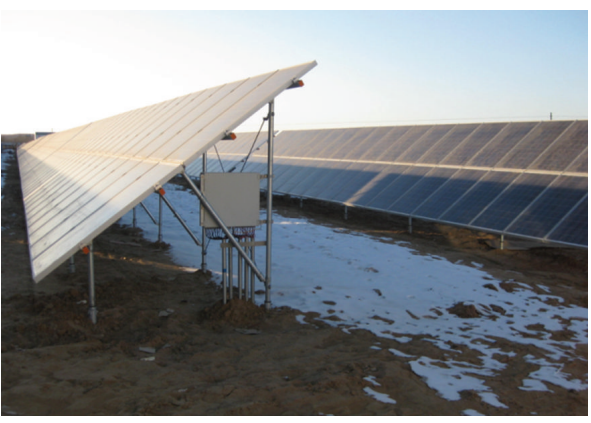

(f)

Figure 3: Different types of shading in a large scale grid-connected PV plant in northwest China. (a) Power distribution buildings shading; (b) wire poles shading; (c) plants shading; (d) bird droppings shading; (e) tracking PV system shading; (f) fixed PV system shading.

TABLE 2: The measurement results in shading effect experiments.

\begin{tabular}{|c|c|c|c|c|c|c|}
\hline Shading proportion & $0 \%$ & $25 \%$ & $50 \%$ & $75 \%$ & $100 \%$ & Nominal \\
\hline$V_{\mathrm{oc}} V_{\mathrm{oc}}(\mathrm{V})$ & 21.65 & 21.63 & 21.62 & 21.62 & 20.97 & 21.7 \\
\hline$I_{\mathrm{sc}}(\mathrm{A})$ & 3.36 & 3.36 & 3.36 & 3.36 & 3.36 & 3.31 \\
\hline$V_{\text {mpp }}(\mathrm{V})$ & 17.64 & 18.67 & 19.62 & 7.40 & 7.84 & 17.4 \\
\hline$I_{\mathrm{mpp}}(\mathrm{A})$ & 3.12 & 2.63 & 1.89 & 3.28 & 3.07 & 3.11 \\
\hline$P_{\mathrm{mpp}}(\mathrm{W})$ & 55.19 & 49.21 & 37.15 & 24.31 & 24.14 & 54 \\
\hline $\mathrm{FF}(\%)$ & 76 & 68 & 51 & 33 & 34 & 75 \\
\hline
\end{tabular}

arrays grow strong and a number of sparrows live in groups near the site of the PV power plant, which cause mass of plants and bird droppings shading on PV modules, as shown in Figures 3(c) and 3(d). The features of this kind of shadow are relatively of small area and of random shape and distribution.
Thus, it is needed to check and clean the modules in PV power plants one by one to completely rule out the shading.

3.1.3. Shading Caused by Front Rows of PV Arrays. According to on-site observation, the shading caused by front rows of 
TABLE 3: Key parameters of the PV module under STC.

\begin{tabular}{lc}
\hline Sample & HH220(30)p \\
\hline$V_{\text {oc }} V_{\text {oc }}(\mathrm{V})$ & 36 \\
$I_{\text {sc }}(\mathrm{A})$ & 8.19 \\
$V_{\text {mpp }}(\mathrm{V})$ & 29 \\
$I_{\text {mpp }}(\mathrm{A})$ & 7.59 \\
$P_{\text {mpp }}(\mathrm{W})$ & 220 \\
\hline
\end{tabular}

PV arrays appears when the solar altitude angle is relatively small in early morning or late afternoon. Figures 3(e) and 3(f) show the shadows falling on the PV modules of tracking PV system and fixed PV system by front rows modules, respectively, which affected the rear rows arrays from 8:40 a.m. to $4: 10$ p.m. on the day when these two photographs were taken in November. This type of shading is due to the improper distance between the adjacent PV arrays. The differences of topography and surface structures between actual terrain and topographic contour map result in the construction processes of PV arrays being difficult to exactly match with the preliminary design, and the distance between the adjacent two arrays is too close, which causes the front row shading in the case of small solar height angle.

\subsection{The Effect of Shading on the Characteristics of PV Modules.} A series of experiments were conducted on-site for these typical shading forms for evaluation and comparison. The studied HH220(30)p PV modules, produced by Huanghe Corporation, include three bypass diodes and $60156 \times$ $156 \mathrm{~mm}^{2}$ polycrystalline silicon solar cells connected in series. The key PV module parameters under standard test conditions are listed in Table 3 . The on-site experiments were conducted on September 12, 2012, from 10:00 a.m. to 11:00 a.m. with fine weather and clear sky. The solar irradiance is steady at about $850 \mathrm{~W} / \mathrm{m}^{2}$. The $I-V$ curves were measured by an $I-V 400 \mathrm{PV}$ Tester made by HT Italia, which can convert the $I-V$ curves at arbitrary condition to the curve under STC.

3.2.1. Effect of Wire Pole Shading. To collect and transport the electricity generated by PV modules, a lot of wire poles were set up around the arrays. However, some of them, located at inappropriate position, would create shadows and spread on several modules surface to block solar irradiance for almost all the daytime. Figure 4 shows the shadow of a wire pole falling on 5 adjacent PV modules, where four of them were numbered as number 1 to number 4 , as shown also in Figure 4. The shadow on the module left next to number 4 module faded away in less than $10 \mathrm{~min}$ before measurement, so the module does not analyze in this section. The number $5 \mathrm{PV}$ module is considered to be a reference as the module with no shadow on it. The $I-V$ and $P-V$ curves of number 1 to number 5 modules were detected rapidly by HT Italia PV Tester I-V400; the main parameters are listed in Table 4 and presented in Figures 6(a) and 6(b).

As the studied PV modules include 3 bypass diodes as shown in Figure 5, the $I-V$ curves present 3 steps as shown in Figure 6(a) and there are 3 peaks in the $P-V$ characteristics in

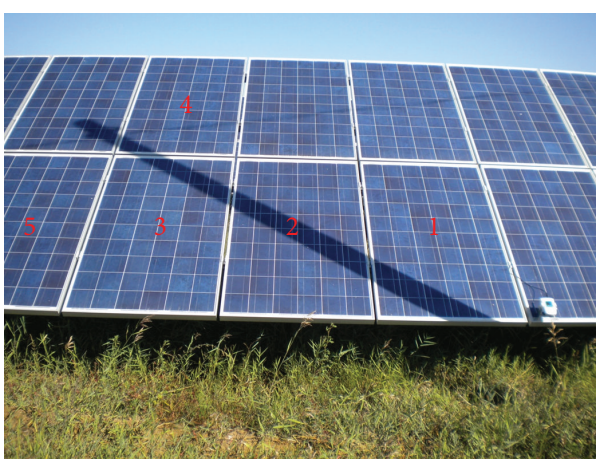

Figure 4: The numbers of the PV modules shaded by wire pole.

Figure 6(b). Detailed analysis was carried out for the number 1 module. There are 3 groups of 20 serially connected solar cells, and parallel connected with one bypass diode for each group, which are $G_{1-1}, G_{1-2}$, and $G_{1-3}$ from right to left as shown in Figure 4. Because the maximum shading areas for one solar cell in each groups are $22.5 \%, 90 \%$, and $96 \%$, the photocurrents have relationship of $I_{\mathrm{ph} 1}>I_{\mathrm{ph} 2}>I_{\mathrm{ph} 3}$. As mentioned in Section 2.1, the characteristics of only Group $G_{1-1}$ are displayed in the curve if the output current is obtained of $I_{\mathrm{ph} 1} \geq I>I_{\mathrm{ph} 2}>I_{\mathrm{ph} 3}$ and the bypass diodes parallel connected with $G_{1-2}$ and $G_{1-3}$ are conducted. While the output current is in the stated $I_{\mathrm{ph} 1}>I_{\mathrm{ph} 2} \geq I>I_{\mathrm{ph} 3}$, the combination characteristics of $G_{1-1}$ and $G_{1-2}$ are presented for the activation of the $G_{1-3}$ bypass diode, and the characteristic of the complete module including $G_{1-1}, G_{1-2}$ and $G_{1-3}$ is plotted in the curve when the output current $I$ is less than the photocurrents, that is, $I_{\mathrm{ph} 1}>I_{\mathrm{ph} 2}>I_{\mathrm{ph} 3} \geq I$, with the circuits of three bypass diodes open.

Since the maximum shading areas for one solar cell in each group of number 2 module from right to left were $96 \%, 90 \%$, and $96 \%$ and of number 3 module $96 \%$, $50 \%$, and $0 \%$, while $0 \%, 90 \%$, and $96 \%$ for number 4 module, as the output currents of modules are negative correlated to the areas of shading, the shapes of the $I$ $V$ curves consequently reveal as 3 steps, and 3 peaks to the $P-V$ curves for they are the integrations of each $I-V$ curves, the local minimum value points in the $P-V$ curves are the state switching points of the bypass diodes. The solar irradiance to the shadow region is about $80 \mathrm{~W} / \mathrm{m}^{2}$ detected by $I-V 400$, the output characteristic can also be measured in the curves, even if the whole cell covered by shadow. As number 5 module was under the full illumination, the shape of output characteristic is consistent with the standard curves.

Although the wire pole that caused shadow area is not large, the narrow and long shape of shadow spreading on several groups of solar cells of some adjacent modules also severely reduced the power output of the modules or even the PV arrays. To avoid the influence of wire pole shading on PV arrays, the most effective solution is to carefully set up the poles and configuration of cables with detailed analysis in the design stage of PV power plant. 
TABLE 4: Key parameters of the PV modules shaded by the wire pole under STC.

\begin{tabular}{|c|c|c|c|c|c|c|}
\hline & 1 & 2 & 3 & 4 & 5 & Nominal \\
\hline$V_{\mathrm{oc}} V_{\mathrm{oc}}(\mathrm{V})$ & 35.99 & 36.05 & 36.04 & 35.99 & 36.05 & 36 \\
\hline$I_{\mathrm{sc}}(\mathrm{A})$ & 6.41 & 2.45 & 8.14 & 7.55 & 8.21 & 8.19 \\
\hline$V_{\text {mpp }}(\mathrm{V})$ & 31.99 & 32.52 & 19.13 & 7.12 & 27.16 & 29 \\
\hline$I_{\mathrm{mpp}}(\mathrm{A})$ & 1.10 & 1.18 & 5.10 & 6.61 & 7.57 & 7.59 \\
\hline$P_{\mathrm{mpp}}(\mathrm{W})$ & 35.26 & 38.32 & 97.61 & 47.01 & 205.53 & 220 \\
\hline $\mathrm{FF}(\%)$ & 15 & 43 & 33 & 17 & 69 & 75 \\
\hline
\end{tabular}

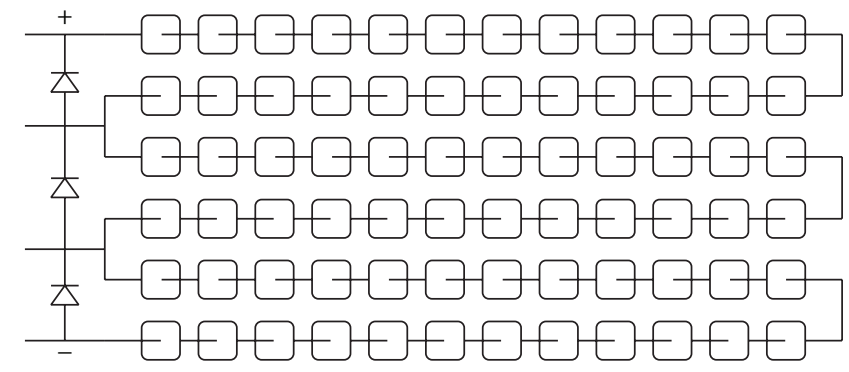

FIgURE 5: A schematic diagram of the PV module HH220(30)p.

3.2.2. Effect of Plants and Bird Droppings Shadings. Plants and bird droppings are very common to become shadings on PV modules. It was found that plants around PV arrays grow strong and number of sparrows live in groups near the site of the studied PV plants, causing mass of plants and bird droppings shading on PV modules. The output characteristics of the PV module shaded by plants were measured before and after the removal of the plant by $I-V 400$ tester. The parameters are listed in Table 5; the $I-V$ and $P-V$ curves are presented in Figure 7.

The shadow caused by the plant as shown in Figure 3(c) is relatively small in area and random in shape, but its falling on all the three groups of cells by each group connected one bypass diode in parallel; the $I-V$ curve displays 3 steps and $P-V$ curves shows 3 peaks shape. Comparing with the maximum power of $215.34 \mathrm{~W}$ after the plant is removed, the output power under shading is just $107.93 \mathrm{~W}$, which was reduced by $50.12 \%$.

In addition, the bird dropping shading is also classified into the small area and random shape shading situation. The output characteristics of the PV module, as shown in Figure 3(d), were measured before and after the removal of the bird droppings by using $I-V 400$ tester. The parameters are presented in Table 6 , and the $I-V$ and $P-V$ curves are illustrated in Figure 8.

As shown in Figure 8, the shadow area caused by bird droppings was small and only affected one of the three groups of the module, so its impact on the output characteristics of $I-V$ and $P-V$ is relatively low. Based on Table 6, Comparing with the output parameters of the module after the bird droppings removal, the maximum output power $P_{\text {mpp }}$ was only reduced by $1 \mathrm{~W}$ and fill factor FF fell by $1 \%$. The shape of the $I-V$ curve of the shaded module reveals a one-step shape; though the step is tiny, it is demonstrated that the forward bias voltage applied on the bypass diode is larger than the voltage
TABLE 5: Key parameters of the PV modules shaded by plant under STC.

\begin{tabular}{lccc}
\hline & Shading & Clear & Nominal \\
\hline$V_{\text {oc }} V_{\text {oc }}(\mathrm{V})$ & 35.99 & 36.02 & 36 \\
$I_{\text {sc }}(\mathrm{A})$ & 7.53 & 8.49 & 8.19 \\
$V_{\text {mpp }}(\mathrm{V})$ & 21.25 & 27.27 & 29 \\
$I_{\text {mpp }}(\mathrm{A})$ & 5.08 & 7.90 & 7.59 \\
$P_{\text {mpp }}(\mathrm{W})$ & 107.93 & 215.34 & 220 \\
FF $(\%)$ & 40.00 & 70.00 & 75 \\
\hline
\end{tabular}

TABLE 6: Key parameters of the PV modules shaded by bird litter under STC.

\begin{tabular}{lccc}
\hline & Shading & Clear & Nominal \\
\hline$V_{\text {oc }} V_{\text {oc }}(\mathrm{V})$ & 35.98 & 35.97 & 36 \\
$I_{\text {sc }}(\mathrm{A})$ & 8.46 & 8.43 & 8.19 \\
$V_{\text {mpp }}(\mathrm{V})$ & 27.36 & 27.82 & 29 \\
$I_{\text {mpp }}(\mathrm{A})$ & 7.91 & 7.82 & 7.59 \\
$P_{\text {mpp }}(\mathrm{W})$ & 216.51 & 217.57 & 220 \\
FF $(\%)$ & 71 & 72 & 75 \\
\hline
\end{tabular}

threshold $V_{\text {th }}$ which is $0.5 \mathrm{~V}$ for silicon diode, activating the bypass diode. If the shadow area was too small, the bypass diode would not conduct because of the applied forward bias voltage is lower than the voltage threshold, which results in the hot-spot effect at the position of the shading and finally causing damage to the solar cell and PV module.

Based on the effect of plants and bird droppings shading discussed above, it is illustrated that the smaller the area of the shadow is, the more dangerous is that to the solar cells and PV modules for that would induce hot-spot effect to damage the materials of the modules, and the more critical it is for us 


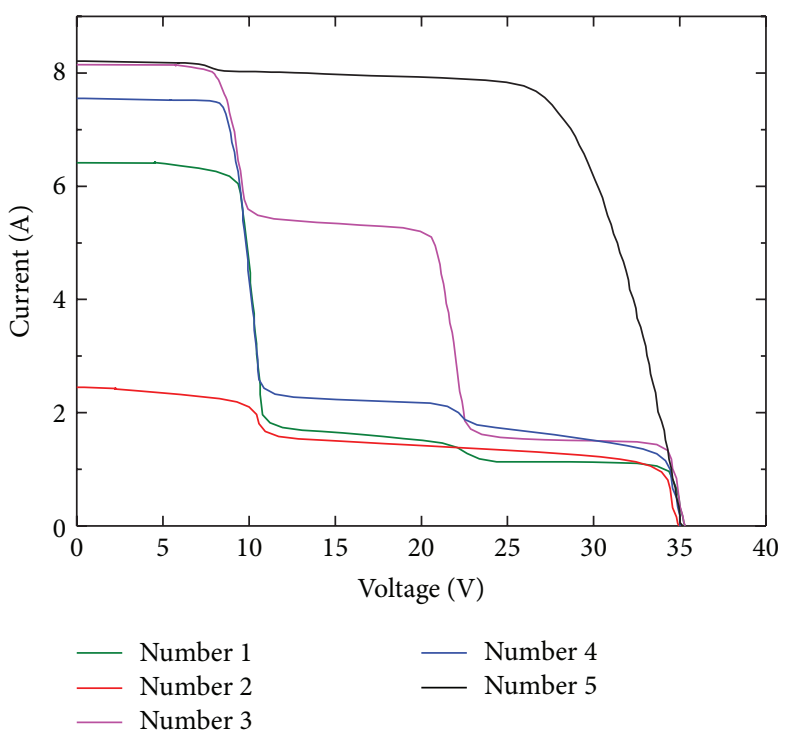

(a)

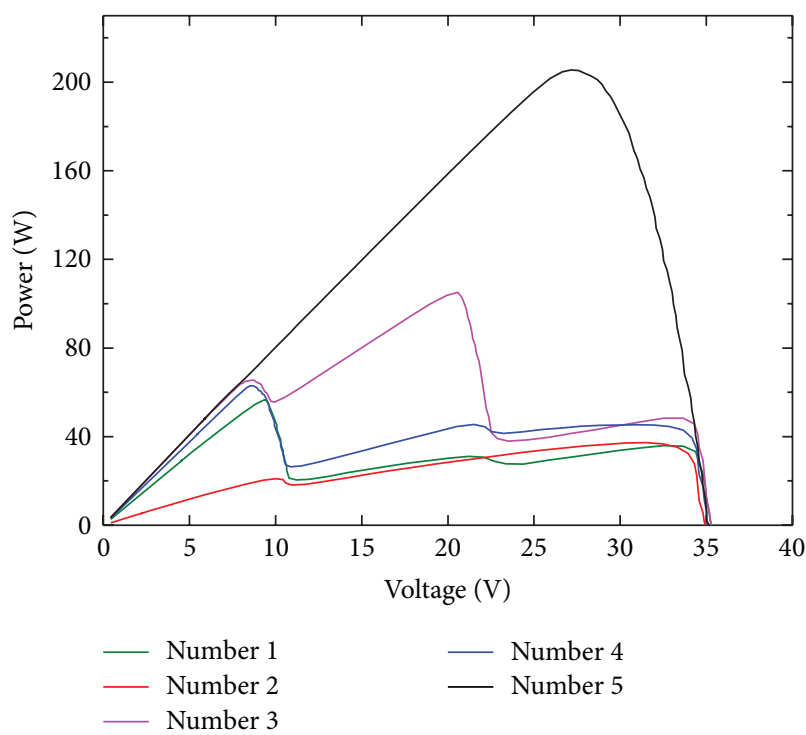

(b)

Figure 6: $I-V$ curves and $P-V$ curves of the five shaded PV modules. (a) $I-V$ curves; (b) $P-V$ curves.

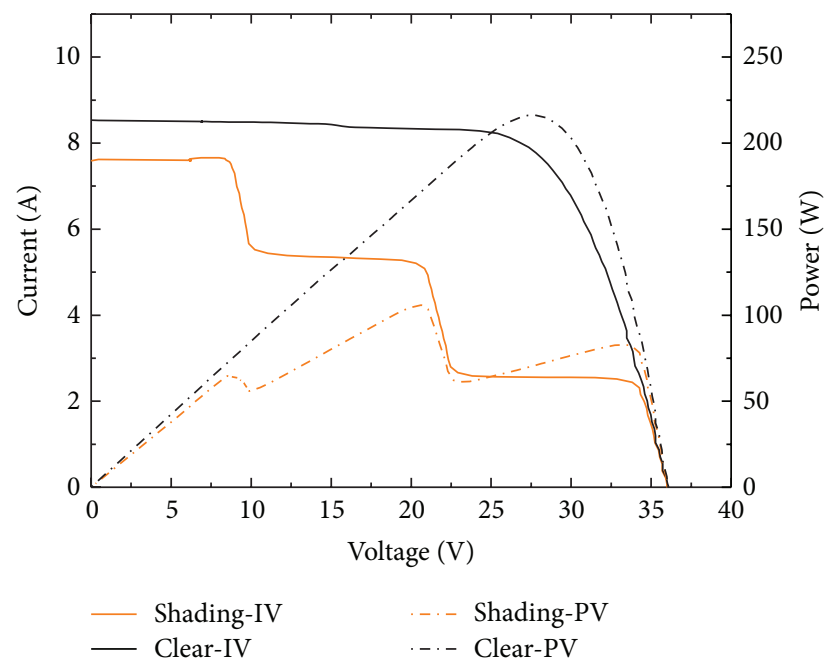

Figure 7: The $I-V$ and $P-V$ characteristics of the module before and after the plant removal.

to remove the small area obstructions. Hence, plants around PV array getting trim and PV modules surface cleaning must proceed periodically during the PV plant operation and maintenance. Moreover, planting scrubs and setting up antibird devices can also be considered in this situation.

\subsubsection{Effect of Shading Caused by Front Rows of PV Arrays.} Distance setting between the two PV arrays is essential for the design stage of the PV system. The installation must follow the basis that at a site of certain latitude and longitude, from 9:00 a.m. to 3:00 p.m. on the winter solstice, the front PV arrays cause no shadow to the rear arrays at least by a distance between them, which is the minimum distance setting to

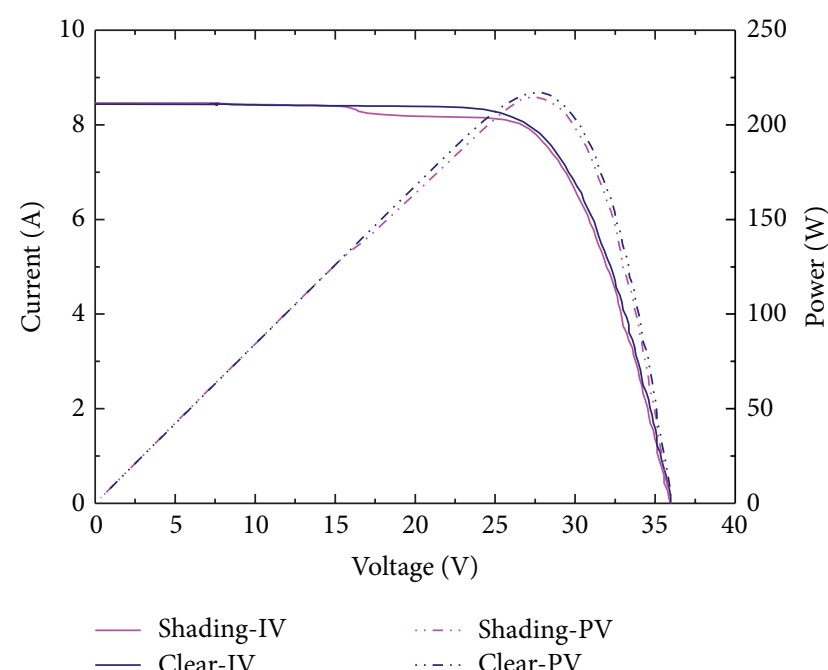

FIgURE 8: The $I-V$ and $P-V$ characteristics of the module before and after the bird droppings removal.

PV arrays configuration, whereas, because of the differences of the terrain and geological condition of the installation location, the PV arrays cannot be constructed in the distance consistent with the exact design setting, thus causing the shading to the PV modules by their front rows $[15,16]$. This type of shadow is large in area and usually covering at the bottom side of the array for more than one complete solar cell in the groups; as can be seen in Figures 3(e) and 3(f), the very low output current of the groups will reduce the output power of the PV arrays and even the entire PV system.

As the solution, it is crucial for site selection of the PV plants, so adequate consideration to the terrain and geological condition of the installation location should be very helpful. 
Besides, using the concept of bypass diodes in PV modules for reference, some bypass diodes are parallel connected with several serially connecting PV modules or arrays [17-20], insuring that the fully illuminated modules completely output their power generated, and reducing the power losses of PV arrays resulting with the so many modules shaded by shadows.

\section{Conclusion}

Shading effect is one of the influence factors resulting in power output reduction of PV modules and arrays. To protect against hot-spots emerging in the partial shaded PV modules, connecting a bypass diode with reverse polarity in parallel to a group of solar cells in serial connection of the module is one of the most common strategies applied in current commercial product. In this paper, a shading simulation model for PV modules was verified under the standard testing condition (STC) in laboratory; it was demonstrated that the total performance of the shaded module was the characteristics additive combination of the groups including some of the serially connecting cells which are connected with bypass diodes in parallel; the characteristics of the group are determined by the solar cell which is shaded by the maximum area of shadow, for the output current of the group, and even the PV module is forced to be equal to that of the maximum area shaded solar cell.

In addition, the modules characteristics of three types of shading that are wire pole shading, plants and bird litter shading, and front rows PV array shading observed in the large-scale grid-connected PV plant in northwest China were detected and analyzed depending on the laboratory experiments. The field investigation results illustrate that the area of shadows caused by wire pole and plants are not so large, but the shadows spread on several serial connecting groups of solar cell for some adjacent modules in many cases; it severely reduces the output power of the modules and even the PV arrays; the bird litter shading impacts on the output characteristics are relatively low for the small area; however, too small area of shadow could not activate the bypass diode because of the applied forward bias voltage lower than the voltage threshold of the diode, resulting in the formation of hot-spot. This paper also proposes some solutions to mitigate the shading effects of power distribution buildings and wire poles, plants and bird litters, and the shadow caused by front rows of PV arrays, offering some ideas for the design, operation, and maintenance of PV power generation.

\section{Conflict of Interests}

The authors declare that there is no conflict of interests regarding the publication of this paper.

\section{Acknowledgments}

This work was financially supported by Scientific and Technological Project in Guangzhou (2011Y1-0006) and
Guangdong Province Enterprise-University-Research Institute Cooperation Innovation Platform of Science and Technology (2012B090600041).

\section{References}

[1] http://solargis.info/doc/71.

[2] K. Morita et al., "Correlation between the change of the appearance and reduction in the output power of crystalline $\mathrm{Si}$ solar cell modules by outdoor exposure," in Proceedings of the JSES/JWEA Joint Conference, pp. 287-290, 2000.

[3] D. Uchida, K. Otani, and K. Kurokawa, "Evaluation of effective shading factor by fitting a clear-day pattern obtained from hourly maximum irradiance data," Solar Energy Materials and Solar Cells, vol. 67, no. 1-4, pp. 519-528, 2001.

[4] J. Appelbaum and J. Bany, "Shadow effect of adjacent solar collectors in large scale systems," Solar Energy, vol. 23, no. 6, pp. 497-507, 1979.

[5] J. Munoz, E. Lorenzo, F. Martínez-Moreno, L. Marroyo, and M. García, "An investigation into hot-spots in two large gridconnected PV plants," Progress in Photovoltaics, vol. 16, no. 8, pp. 693-701, 2008.

[6] A. Woyte, J. Nijs, and R. Belmans, "Partial shadowing of photovoltaic arrays with different system configurations: literature review and field test results," Solar Energy, vol. 74, no. 3, pp. 217233, 2003.

[7] J. C. Arnett and C. C. Gonzales, "Photovoltaic module hot spot durability design and test methods," in Proceedings of the 15th IEEE Photovoltaic Specialists Conference, pp. 1099-1105, 1981.

[8] E. Karatepe, M. Boztepe, and M. Çolak, "Development of a suitable model for characterizing photovoltaic arrays with shaded solar cells," Solar Energy, vol. 81, no. 8, pp. 977-992, 2007.

[9] S. Silvestre, A. Boronat, and A. Chouder, "Study of bypass diodes configuration on PV modules," Applied Energy, vol. 86, no. 9, pp. 1632-1640, 2009.

[10] H. Kawamura, K. Naka, N. Yonekura et al., "Simulation of IV characteristics of a PV module with shaded PV cells," Solar Energy Materials and Solar Cells, vol. 75, no. 3-4, pp. 613-621, 2003.

[11] R. Ramaprabha, "Effect of shading on series and parallel connected solar PV modules," Modern Applied Science, vol. 3, no. 10, pp. 32-41, 2009.

[12] M. Meinhardt G Cramer, "Multi-string-converter the next step in evolution of string-converter technology," in Proceedings of Evolution of the European Power Electronics Conference, 2001.

[13] M. Drif, P. J. Pérez, J. Aguilera, and J. D. Aguilar, "A new estimation method of irradiance on a partially shaded PV generator in grid-connected photovoltaic systems," Renewable Energy, vol. 33, no. 9, pp. 2048-2056, 2008.

[14] R. Ramaprabha and B. L. Mathur, "A comprehensive review and analysis of solar photovoltaic array configurations under partial shaded conditions," International Journal of Photoenergy, vol. 2012, Article ID 120214, 16 pages, 2012.

[15] S. Silvestre and A. Chouder, "Effects of shadowing on photovoltaic module performance," Progress in Photovoltaics, vol. 16, no. 2, pp. 141-149, 2008.

[16] P. Spirito V Albergamo, "Reverse bias power dissipation of shadowed or faulty cells in different array configurations," in Proceeding of the 4th E.C. Photovoltaic Solar Energy Conference, pp. 296-300, 1982. 
[17] M. C. Alonso-García, J. M. Ruiz, and F. Chenlo, "Experimental study of mismatch and shading effects in the I-V characteristic of a photovoltaic module," Solar Energy Materials and Solar Cells, vol. 90, no. 3, pp. 329-340, 2006.

[18] A. K. Sharma, R. Dwivedi, and S. K. Srivastava, "Performance analysis of a solar array under shadow condition," IEE Proceedings $G$, vol. 138, no. 3, pp. 301-306, 1991.

[19] H. Bo, N. Yuto, and Y. Ryuichi, "Influence of large-scale grid-connected photovoltaic system on distribution networks," Automation of Electric Power Systems, vol. 36, no. 3, pp. 34-96, 2012.

[20] Y. Wang, H. Yang, Y. Liu et al., "The use of Ti meshes with self-organized $\mathrm{TiO}_{2}$ nanotubes as photoanodes of all-Ti dyesensitized solar cells," Progress in Photovoltaics, vol. 18, no. 4, pp. 285-290, 2010. 

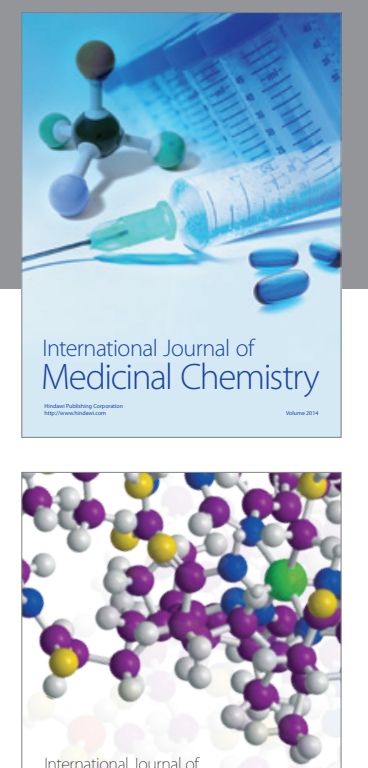

\section{Carbohydrate} Chemistry

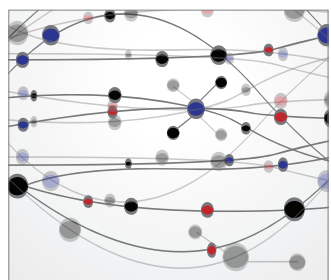

The Scientific World Journal
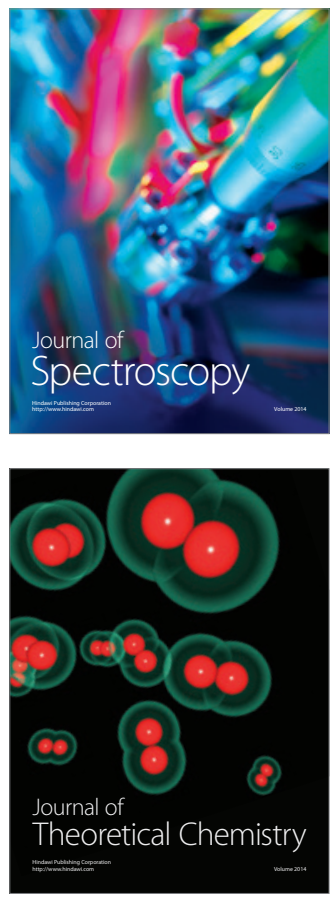
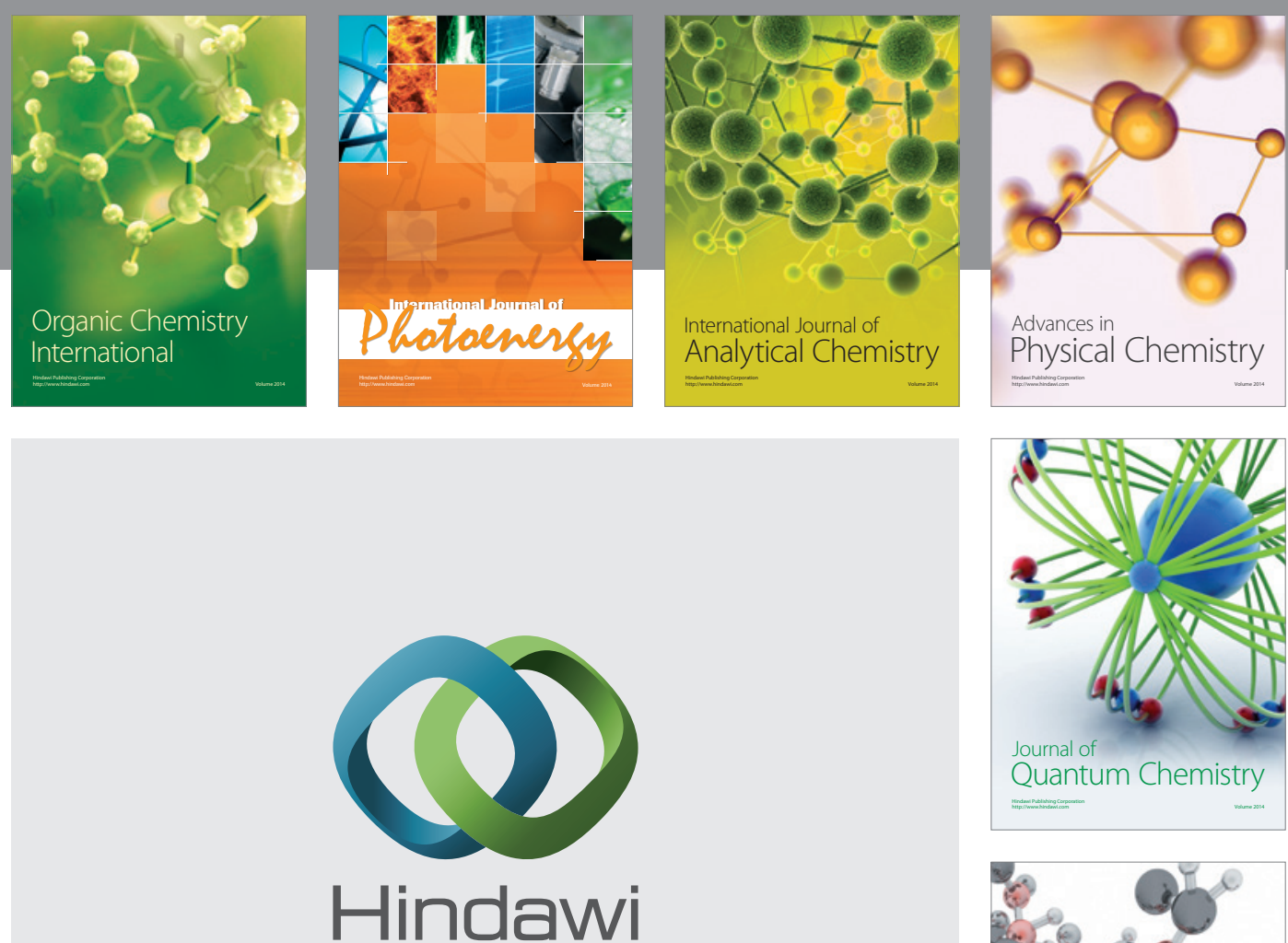

Submit your manuscripts at

http://www.hindawi.com

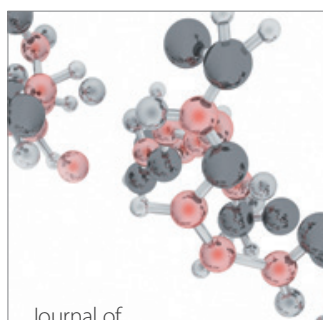

Analytical Methods

in Chemistry

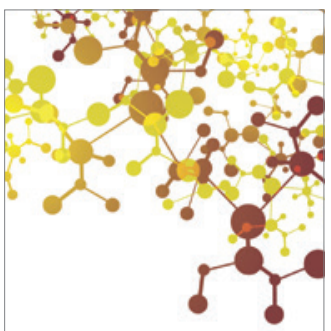

Journal of

Applied Chemistry

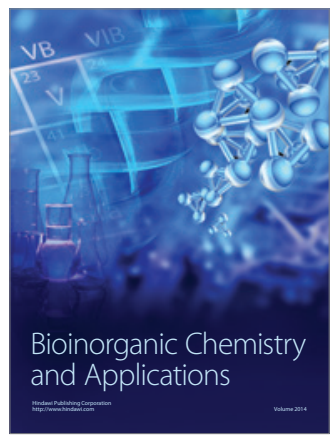

Inorganic Chemistry
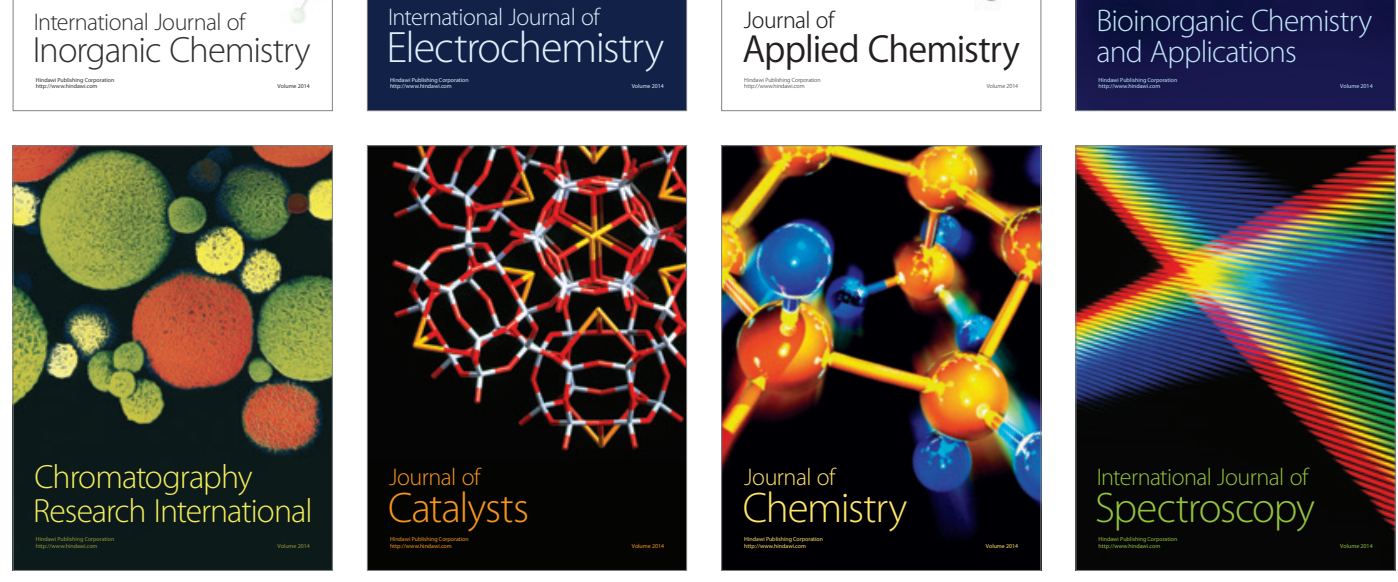